\title{
Model Experimental Study on Wave Dissipation Effect for Double-deck Monomer Floating Structure
}

\author{
ZHOU Chuanwan ${ }^{1, \text { a }}$ SHANG GUAN Zichang ${ }^{2, b}$ SHEN Lü, \\ ${ }^{1,2,3}$ College of Ocean and Civil Engineering Dalian Ocean University, Dalian 116023, China \\ a zhouchuanwan@foxmail.com, ${ }^{\text {b }}$ shangguan@dlou.edu.cn, ${ }^{\mathrm{C}}$ shenlu@dlou.edu.cn
}

\begin{abstract}
Key words: Double-deck monomer; Floating structure; Wave dissipation effect; Model experimental study; Transmission coefficient
\end{abstract}

Abstract: The double-deck monomer floating structure under the rules of two-dimensional wave action for the study of physical model experimental, measuring the wave height behind the structure in the experiment, calculated the transmission coefficient. Based on considering the different water depth, the different ways of putting, the different row numbers, the different materials and with or without net cage to analysis the condition of wave dissipation effect. Water depth in $0.5 \mathrm{~m}$, the model above the water of $0.06 \mathrm{~m}$; Water depth in $0.6 \mathrm{~m}$, the model covered $0.04 \mathrm{~m}$ and the periods were ranging from 0.8 to 1.1 seconds.

Since the 1950s, China's coastal erosion is more and more obvious and damage continues to intensify. Such as The DiaoKou River spit in the Yellow River delta from 1976 to 1986 was eroded about $6 \mathrm{~km}$, erosion area was of $100 \mathrm{~km}^{2}$. From1986 to2002, the corrosion is gone around $1 \mathrm{~km}$, the corrosion area is around $37 \mathrm{~km}^{2}{ }^{[1]}$. one of the important reason about erosion is the impact of ocean waves ${ }^{[2]}$.the impact of the wave caused a loss in China Fisheries and Aquaculture , seriously affected the social economic development and people's living standards. Therefore, the study of coastal zone protection measures, reduce the impact on the deep water aquaculture area of ocean waves is an urgent issue.

Generally measures to prevent coastal erosion mainly include two categories: one is the hard environment, resist the coastline back or cut along the wave energy, such as building breakwater wall, dike, jetty, submerged breakwater, the offshore breakwater etc; second, the soft environment, adopt the methods for simulating the characteristics of coastal systems against coastal erosion, such as filling sand to protect beach, building shelter belt, biological revetment measures. These measures were large Construction, very difficult, working too long, expensive, complex structure and not suitable for deep water aquaculture area, so some floating wave device movement is born, they are construction of small, simple, time short, low cost, light weight and so on relative to the former. In addition, they also do not destroy the waters of the integrity and ecological environment.

There are many floating wave structure type ${ }^{[3-8]}$, in this paper ,it study on a kind of double monomer floating wave structure, especially suitable for the deep waters ${ }^{[9]}$, waves through the model To achieve wave dissipation effect. Through the permeability coefficient to comparative and analysis of wave dissipation effect, then provide reference for practical engineering applications.

\section{Scheme of model experiment}

\section{Test equipment and measuring instruments}

The test was conducted in a wave flume at the Key Laboratory of coastal engineering in Liaoning, Dalian. The sink is $40 \mathrm{~m}$ long, $0.7 \mathrm{~m}$ wide, $1 \mathrm{~m}$ deep. At the end of the sink, the water tank 
is equipped with a wave generating machine, which can generate a wave, irregular wave, and the wave is stable and good repeatability. At the other end of the tank is provided with an energy dissipation device, which is used to absorb the wave energy in order to reduce the wave reflection. The automatic acquisition and analysis of the experimental data is controlled by the microcomputer system. The wave was measured by the DS30 type 64 channel of Wave-Height Gauge. The instrument and equipment are calibrated before and after the test, which can satisfy the requirements of the sensitivity and stability. These conditions provide the necessary guarantee for the successful physical model test.

\section{Test model design}

The device is composed of a buoyancy system, an energy dissipation system and an anchoring system. The test device adopts two kinds of material. One is a one-time injection molding PVC pipe, which has the advantages of acid and alkali corrosion resistance, stiffness. Another material is fine bamboo; its advantage is cheap, easy to draw materials, transportation convenient, less pollution. At both ends of the model is the drilling of the thin wood, hole size and thin bamboo or PVC pipe with the same diameter, thin bamboo or PVC tube sealed at both ends into the pores of the thin board and use the rope tight them. The waterproof foam is glued to the ends of the thin board, the bamboo or the PVC tube, and the two sides are also used to increase the buoyancy. The cage is suspended in the interior of the device by 3 layers of a cage made of bamboo, foam and wood. The anchoring system is made up of concrete block and anchor rope, the anchor rope connecting device and the concrete block, the anchor rope tied on the device is fixed at the end of the device. Then place the device, the four device end with 4 roots with certain strength and toughness of the rope to Connect the concrete block.
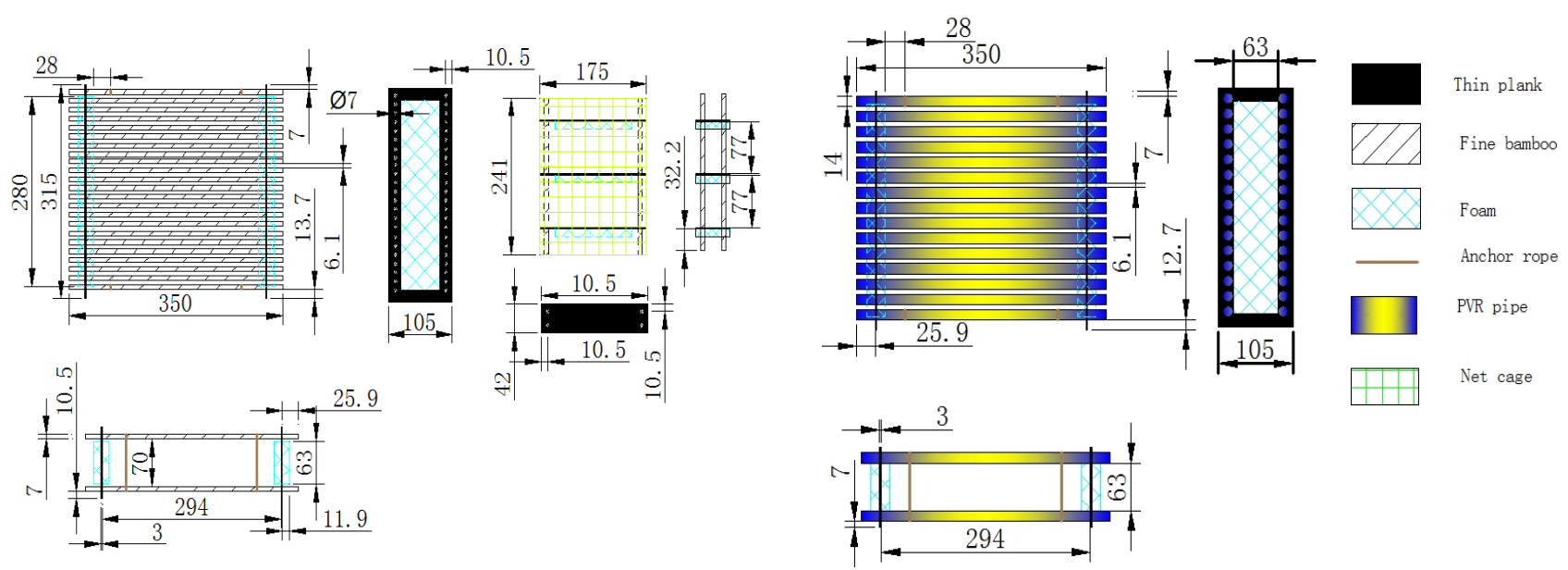

Fig. 1 model Size chart and Schematic diagram （Unit for $\mathrm{mm}$ )

\section{Wave parameters for model test}

The physical model uses regular waves, according to the actual data of Liaoning Yingkou Baishawan and model scale is $1: 30$, test water depth respectively for $0.5,0.6 \mathrm{~m}$, wave period respectively 0.80 and $0.90,1.00,1.10 \mathrm{~s}$. The corresponding wavelength can be $1,1.89,1.56$, and $1.26 \mathrm{~m}$ according to the formula of the regular wave theory. According to the experimental model scale, the actual wave period is $4.38,4.93,5.48,6.02 \mathrm{~s}$. 
Tab.1 wave parameters for model test

\begin{tabular}{cccccc}
\hline $\begin{array}{c}\text { Water } \\
\text { depth } \mathrm{h} / \mathrm{m}\end{array}$ & $\begin{array}{c}\text { Wave height } \\
\mathrm{H} / \mathrm{m}\end{array}$ & \multicolumn{4}{c}{ Wave period T/s } \\
\hline \multirow{2}{*}{0.5} & 0.07 & 0.80 & 0.90 & 1.00 & 1.10 \\
& 0.08 & 0.80 & 0.90 & 1.00 & 1.10 \\
& 0.09 & 0.80 & 0.90 & 1.00 & 1.10 \\
0.6 & 0.07 & 0.80 & 0.90 & 1.00 & 1.10 \\
& 0.08 & 0.80 & 0.90 & 1.00 & 1.10 \\
& 0.09 & 0.80 & 0.90 & 1.00 & 1.10 \\
\hline
\end{tabular}

\section{Experimental parameters}

Tab.2 Symbol description for experimental setup parameters

\begin{tabular}{lc|lc}
\hline Main parameters & Symbol & Main parameters & Symbol \\
& & & \\
\hline Water depth & $\mathrm{h}$ & Relative width & $\mathrm{B} / \mathrm{L}$ \\
Wave height & $\mathrm{H}$ & Transmission coefficient & $\mathrm{Kt}$ \\
Wave period & $\mathrm{T}$ & & \\
Wave length & $\mathrm{L}$ & & \\
Model width & $\mathrm{B}$ & & \\
\hline
\end{tabular}

\section{Experimental model arrangement}

Tests were arranged four wave gauges, intended to be placed at the center position of model placed 4th wave-height gauge in to measuring the original height, In order to meet the test wave elements of table1 and verify the accuracy of wave making machine. The model was arranged in the middle position of the sink to prevent the reflected wave at the two ends of the sink affects the test results. No. 1 and 2 wave-height gauges placed in front of the model, the spacing was $0.5 \mathrm{~m}$, between 0.05Lmax and $0.45 \mathrm{Lmin}$, responsible for collecting the wave change process in front of the model, no. 3 wave-height gauge layout at the end of the model to collect the wave change process in the end of the model. No.2and3 wave-height gauges distance the model were $1 \mathrm{~m}$, greater than $0.02-0.25 \mathrm{~L}$. Each experiment was carried out for three times; take the average of their results.

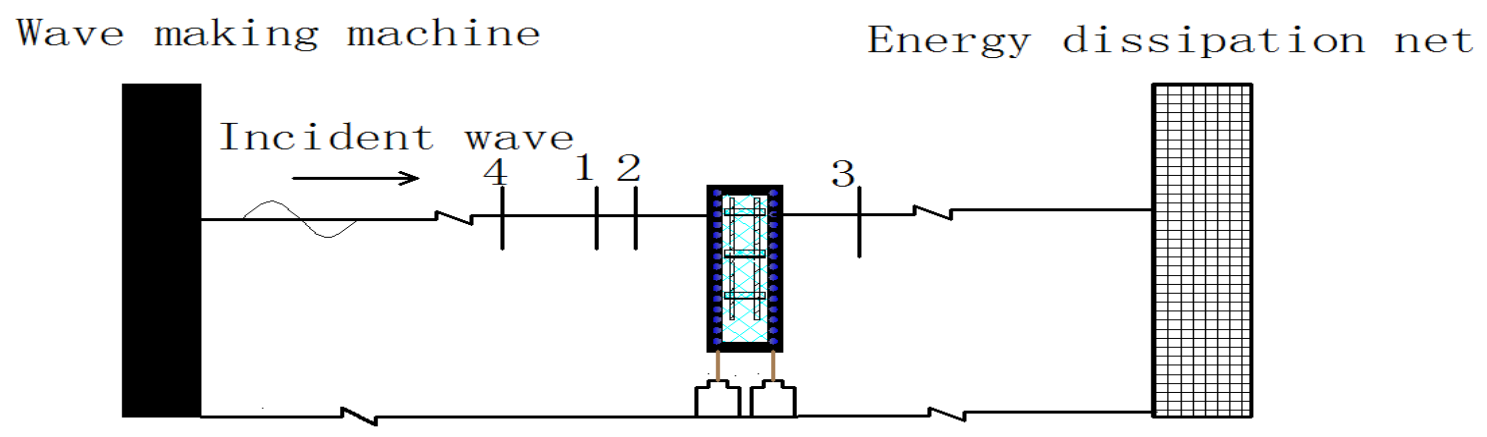

Fig. 2 Details of wave flume and experimental setup

\section{Experimental result analysis}

This paper focuses on the analysis of the wave effect of the double-deck monomer floating structure. The test results of wave transmission coefficient of $\mathrm{Kt}=\mathrm{Ht} / \mathrm{Hi}, \mathrm{Ht}$ is wave height behind 
the model; Hi is wave height after the model.

\section{Effect of water depth on transmission coefficient of model}

From fig.3, it can be seen that the water depth has little effect on the transmission coefficient of double row, but to triple row is relatively large. It means that under the same condition of water depth on the wave dissipation effect of the number of rows are larger.

Double row

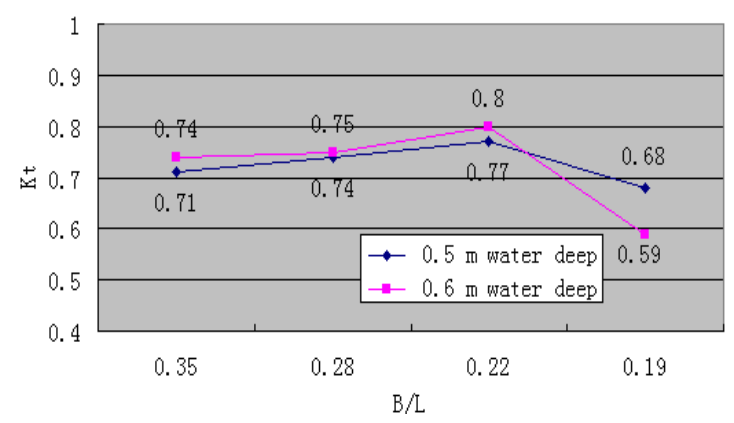

$\mathrm{H}=0.07 \mathrm{~m}$
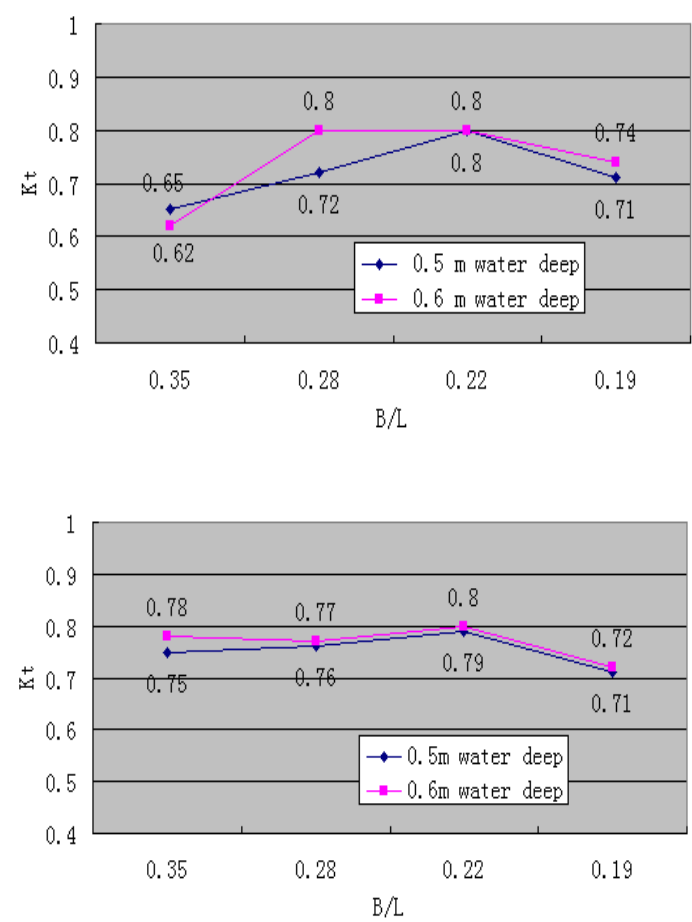

Triple row
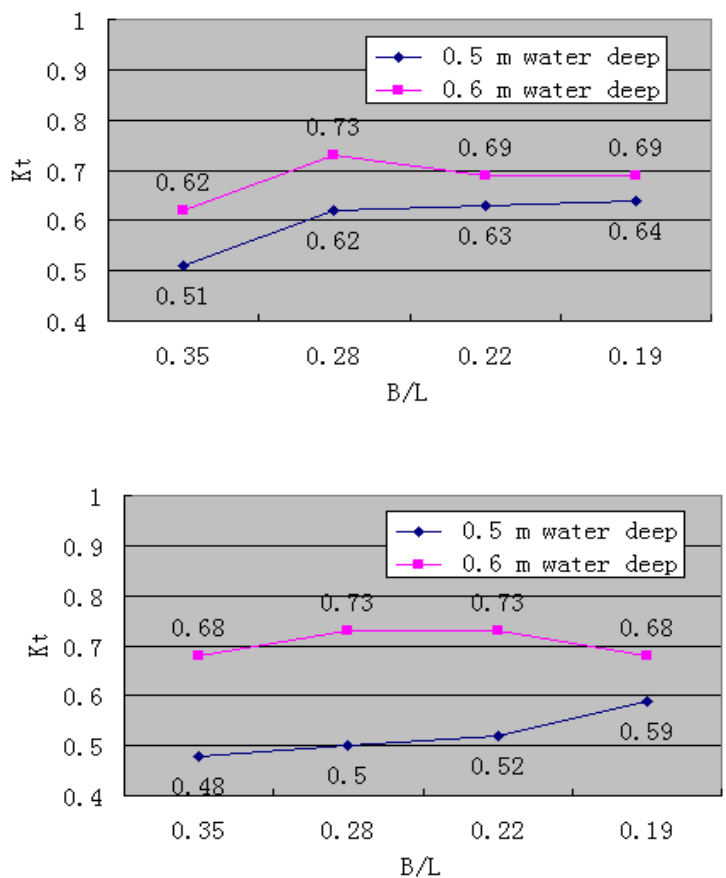

$\mathrm{H}=0.08 \mathrm{~m}$

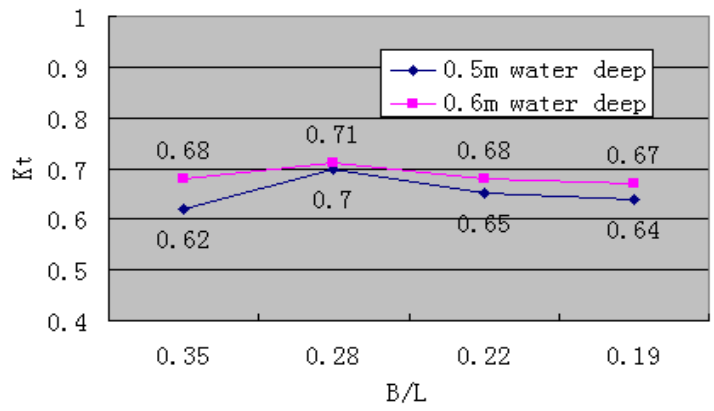

$\mathrm{H}=0.09 \mathrm{~m}$

Fig. 3 Influence of $\mathrm{B} / \mathrm{L}$ and water depth on transmission coefficient $\mathrm{Kt}$

Effect of ways of putting on transmission coefficient of model

From fig.4, it can be seen that the transmission coefficient of horizontal is less than vertical; it means that the wave dissipation effect of horizontal is better than vertical. 
$0.5 \mathrm{~m}$ water deep
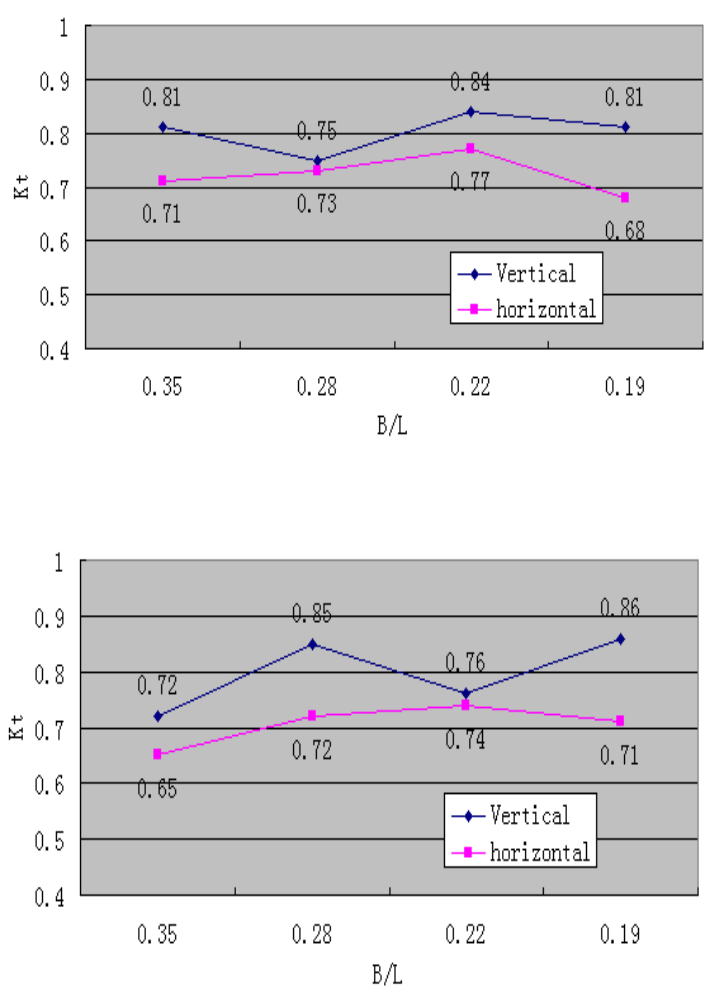

$0.6 \mathrm{~m}$ water deep

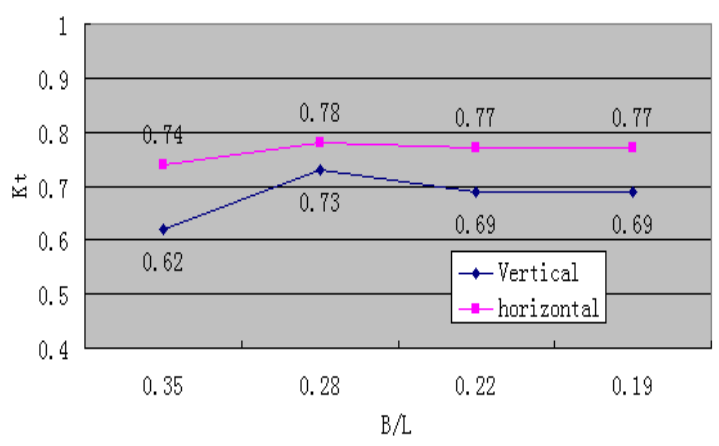

$\mathrm{H}=0.07 \mathrm{~m}$

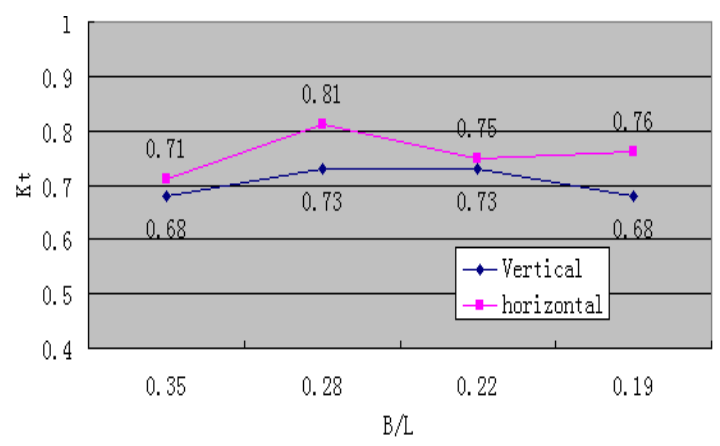

$\mathrm{H}=0.08 \mathrm{~m}$

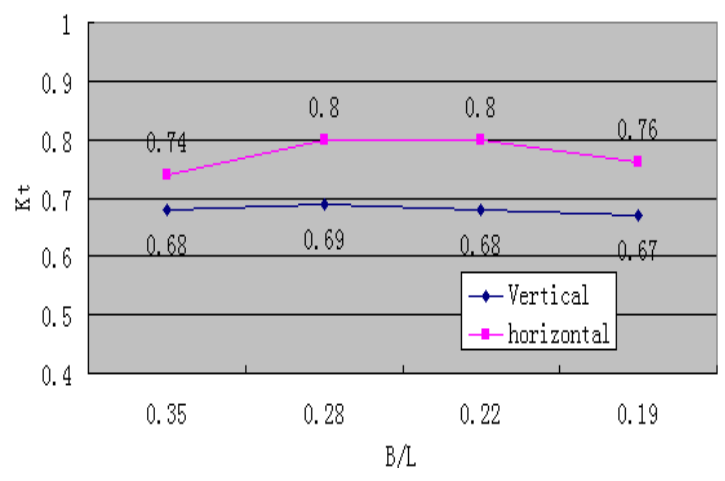

$\mathrm{H}=0.09 \mathrm{~m}$

Fig. 4 Influence of $\mathrm{B} / \mathrm{L}$ and the ways of putting on transmission coefficient $\mathrm{Kt}$

\section{Effect of row numbers on transmission coefficient of model}

From fig.5, it can be seen that the transmission coefficient of double row is less than single row; the transmission coefficient of triple row is less than double row, which shows that the more the number of the rows, the wave dissipation effect is better. 

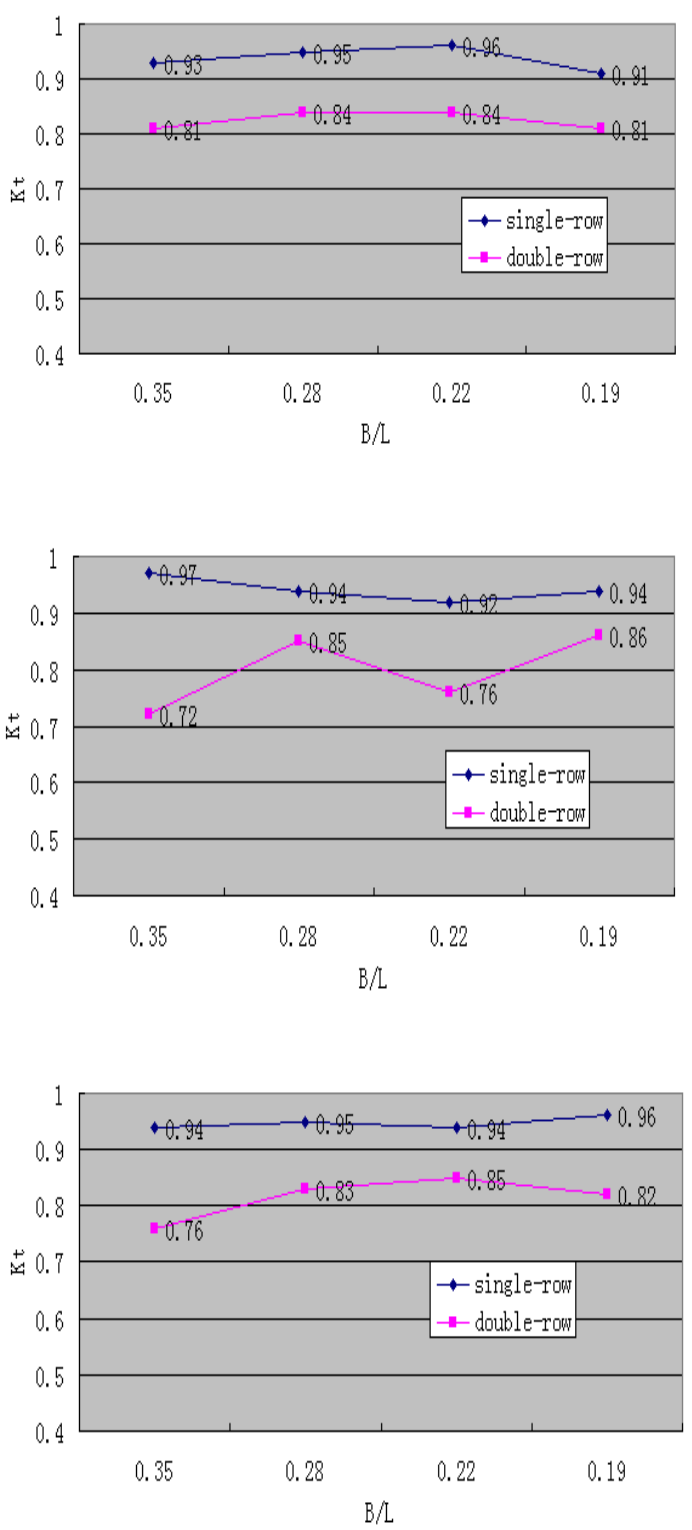

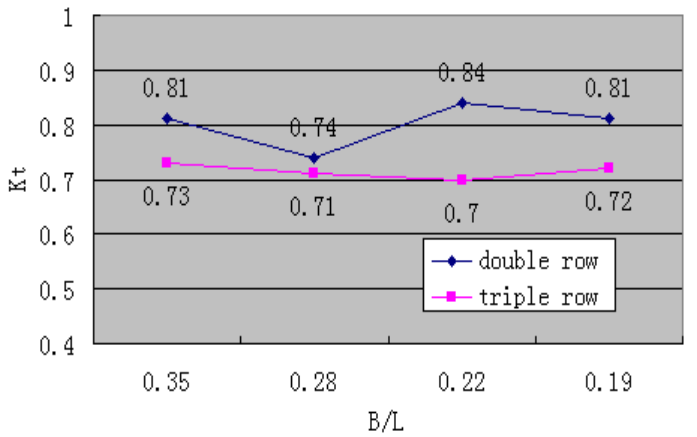

$\mathrm{H}=0.07 \mathrm{~m}$

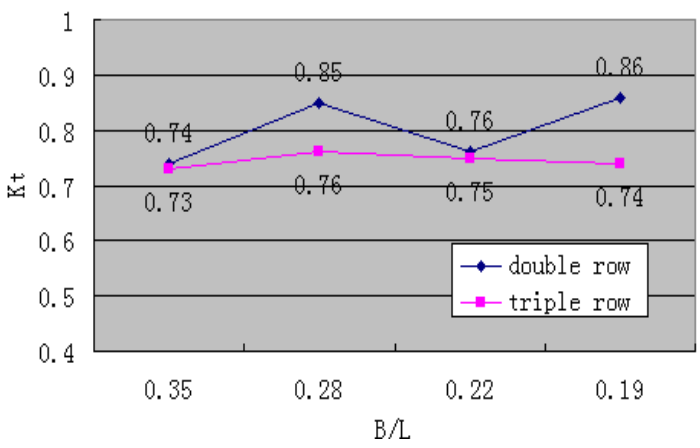

$\mathrm{H}=0.08 \mathrm{~m}$

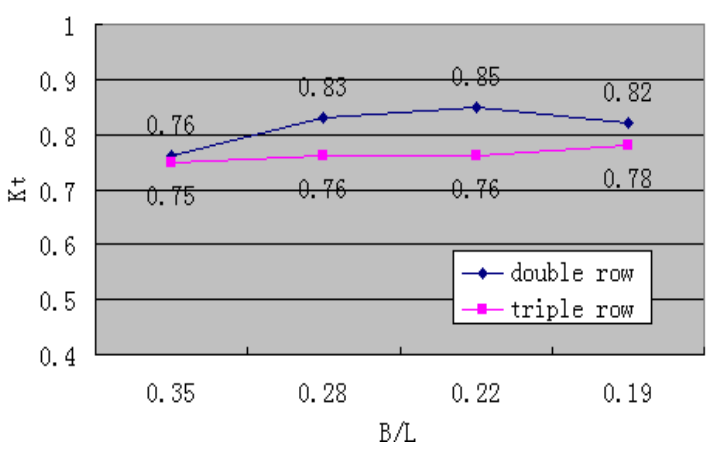

$\mathrm{H}=0.09 \mathrm{~m}$

Fig. 5 Influence of B/L and row number on transmission coefficient $\mathrm{Kt}$

\section{Effect of material and net cage on transmission coefficient of model}

From fig.6, it can be seen that the transmission coefficient of a net cage is smaller than that of without a net cage; it means that the wave dissipation effect of a net cage is good. When the material is not same, it has little effect on the wave dissipation effect. 

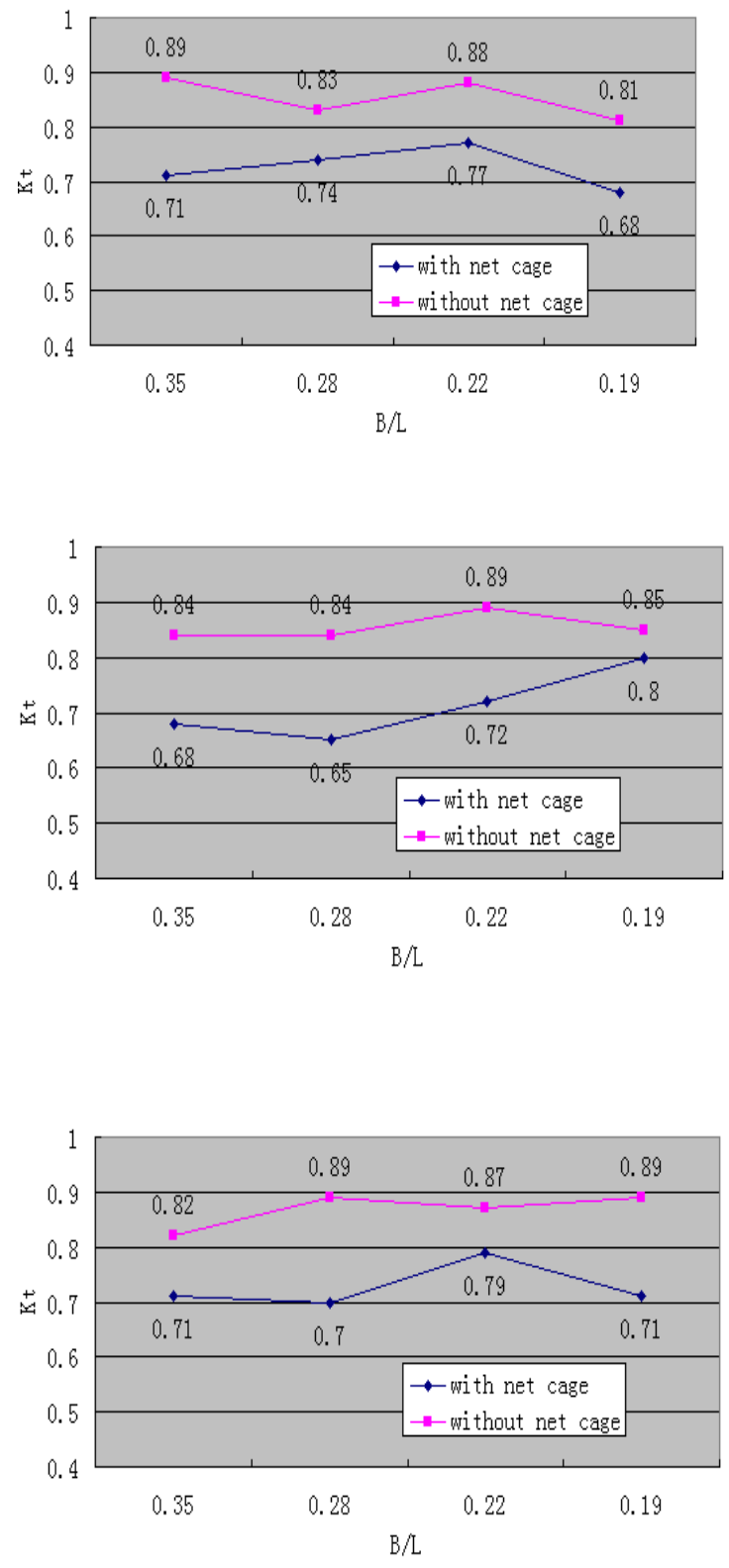

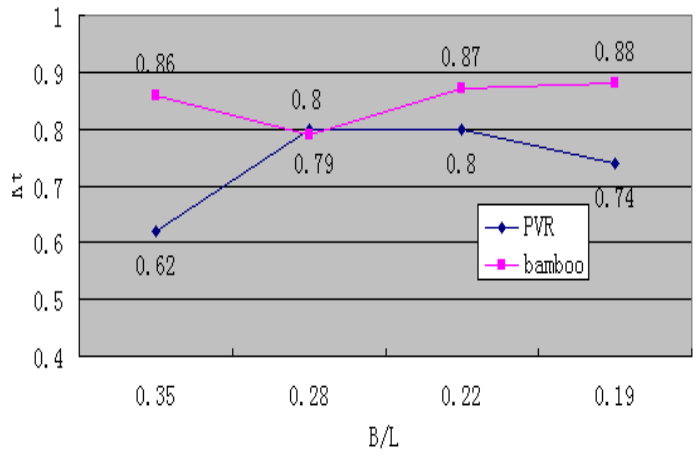

$\mathrm{H}=0.07 \mathrm{~m}$

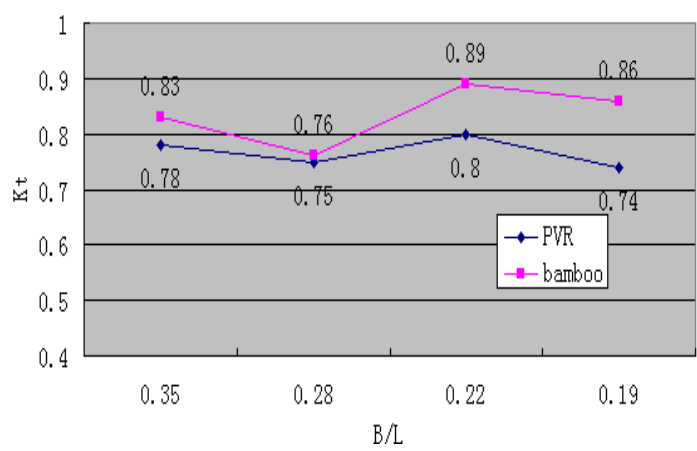

$\mathrm{H}=0.08 \mathrm{~m}$

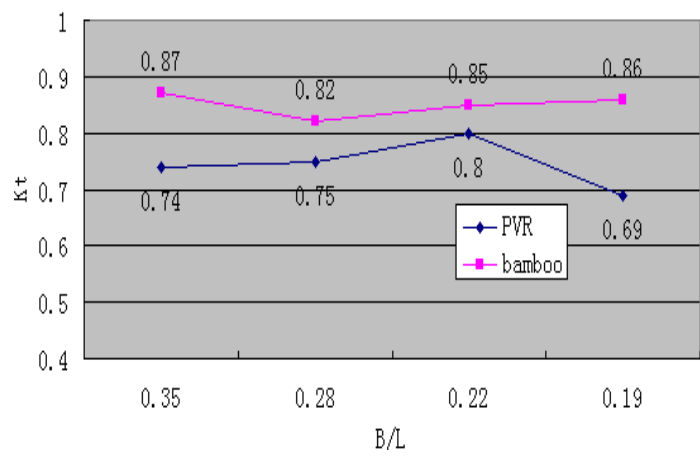

$\mathrm{H}=0.09 \mathrm{~m}$

Fig. 6 Influence of $\mathrm{B} / \mathrm{L}$ and material and net cage on transmission coefficient $\mathrm{Kt}$

\section{Summary}

In this paper, a model experimental study on wave dissipation effect for double-deck monomer floating structure by calculating the transmission coefficient, Experimental results show that the ways of putting and the number of rows have a significant effect on the wave dissipation effect. The wave dissipation effect of horizontal is better than vertical; the more the number of the rows, the wave dissipation effect is better and the influence of water depth on the wave dissipation effect is larger; the wave dissipation effect of a net cage is good; When the material is not same, it has little effect on the wave dissipation effect. 


\section{References:}

[1] Xue Fang, Hu Jinye, Zhang Zifeng etc. Analysis of the current situation of coastal erosion in the Yellow River Delta and the ecological protection measures [J] Shandong Environment, 2003, (6): 23-27.

[2] Wang Wenhai. The causes and countermeasures of Chinese coastal erosion [J]. Marine Development, 1997(1): 8-12.

[3] Wu Jingping, Wang Renkang, Zheng Xiaowei, Jiang Mansong, Shi Jizhu. Experimental study on floating breakwater [J]. Journal of Wuhan University of Technology (Transportation Science \& Engineering) 2001, 25(1): 91-93.

[4] Shunichi Ikesue, Kazumi Tamura, Yasuhio Sugi. Study on the performance of a floating breakwater with two boxes [A]. Proceedings of The Twelfth International Off shore and Polar Engineering Conference [C], Kitakyushu, Japan: ISOPE Press, 2002.773-778.

[5] Nobuhiro Matsunaga, Misao Hashida, Ken-ichi Uzaki. Performance of wave absorption by a steel floating breakwater with truss structure [A]. Proceedings of the Twelfth International Off shore and Polar Engineering Conference [C], Kitakyushu, Japan: ISOPE Press, 2002.768-772. [6] Murali K, Mani J S. Performance of cage floating breakwater [J]. Journal of Waterway, Port, Coastal and Ocean Engineering, 1997, 123(4): 172-179.

[7] Mani J S. Design of Y-Frame floating breakwater [J].Journal of Waterway, Port, Coastal and Ocean Engineering, 1991, 117(2): 105-118.

[8] Bayram Atilla. Experimental study on a sloping float breakwater [J]. Ocean Engineering, 2000, 27: 453-455.

[9]Stein G, Athens M. The LQG/LTR procedure for multivariable feedback control design [J]. IEEE Trans, 1987, 32(2): 105-114. 